\title{
Die Akkreditierung - das Mandat zur Weiterbildung wird erneuert
}

\section{Werner Bauer}

Dr. med., Präsident des Schweizerischen Instituts für ärztliche Weiter- und Fortbildung SIWF

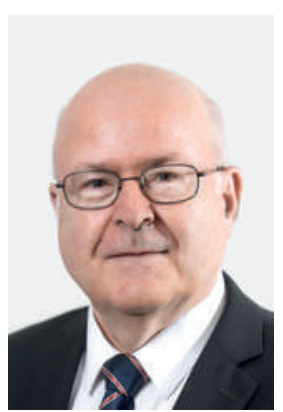

Mit der Einführung der gegenseitigen Diplomanerkennung in Europa wurden die privatrechtlichen Facharzttitel im Jahr 2002 zu eidgenössischen Titeln. Für die FMH und die Fachgesellschaften war essentiell, dass auch weiterhin eine ärztliche Organisation für die Umsetzung der gesetzlichen Vorgaben (Medizinalberufegesetz) und damit für die Strukturierung der Weiterbildung zuständig war. Dies gelang. Die Institution, welche diese Aufgabe als neues Organ der FMH übernahm, ist das Schweizerische Institut für ärztliche Weiter- und Fortbildung SIWF. Es erlässt die Weiterbildungsordnung und gestaltet zusammen mit den Fachgesellschaften die einzelnen Weiterbildungsprogramme. Auf der Grundlage dieser Programme werden die Weiterbildungsstätten anerkannt, die Visitationen durchgeführt und die individuellen Facharzttitel erteilt. Diese Kompetenzen überträgt die Eidgenossenschaft allerdings nicht auf blosser Vertrauensbasis und für einen unbegrenzten Zeitraum. Organisationen wie das SIWF und die Fachgesellschaften, welche eine staatliche Aufgabe wahrnehmen, werden regelmässig mittels Akkreditierung durch das zuständige Eidgenössische Departement des Inneren EDI evaluiert. Diesen Prozess durchlaufen das SIWF als verantwortliche Organisation und jede Fachgesellschaft mit einem eidgenössischen Facharzttitel alle sieben Jahre. Er ist aufwendig, sowohl vom Zeitaufwand als auch von den Kosten her. Ausgangspunkt ist der Selbstevaluationsbericht, in dem eine Reihe von Fragen zu den verschiedensten sogenannten «Qualitätsstandards» beantwortet werden müssen.

Dabei geht es beispielsweise um die Erfüllung folgender Anforderungen: In Notfallsituationen selbständig handeln können. Übernahme von Verantwortung im Gesundheitswesen. Die Beurteilung beinhaltet formative und summative Methoden sowie laufendes Feedback. Eine Beurteilung der Weiterbildung durch die Weiterbildnerinnen und Weiterbildner sowie die Weiterzubildenden geschieht fortlaufend. Es ist ein Massnahmenplan für die Zukunft zu skizzieren (Weiterentwicklung des Weiterbildungsgangs). Die Berichte gehen an ein Expertenteam, dessen Mitglieder jeweils denjenigen ihres Faches studieren und offene Fragen an einem Round-Table-Gespräch zu klä- ren suchen. Auf der Basis von Bericht und Gespräch verfassen die Experten ihre Rapporte, die dann noch von der Medizinalberufekommission (MEBEKO) kommentiert werden können. In die Beurteilung können bei erkanntem Bedarf Empfehlungen oder Auflagen einfliessen, an deren Umsetzung die Akkreditierung geknüpft werden kann. Das Organisatorische des Prozedere liegt bei der Agentur für Akkreditierung und Qualität (AAQ), die Oberhoheit beim Bundesamt für Gesundheit (BAG) und beim EDI, welches dann auch die Verfügungen erlässt.

Warum ist die Akkreditierung Thema für ein Editorial? Drei Gründe:

- Das schweizerische Modell der Regelung und Realisierung der Weiterbildung ist bemerkenswert schlank,

Die Akkreditierung sollte als Chance genutzt werden, Vorstellungen für die Zukunft der Weiterbildung zu entwickeln.

effizient und ein Beispiel funktionierender Zusammenarbeit einer standeseigenen (SIWF) und einer staatlichen Institution (BAG).

- Die Akkreditierung ist für die Miliz-Fachgesellschaften sehr aufwendig. Deshalb stösst sie nicht nur auf Akzeptanz, sondern da und dort auf ärgerliches Unverständnis. Dazu gilt es in Erinnerung zu rufen, dass die Freiheit, die Weiterbildung weitgehend in ärztlichen Händen zu gestalten, halt auch mit Pflichten verbunden ist, denen wir uns nicht entziehen können. Die Akkreditierung kann zudem zusätzlichen Sinn gewinnen, wenn wir sie als Gelegenheit nutzen, uns über die Zukunft der ärztlichen Bildung vertieft Gedanken zu machen.

- Wir möchten die AAQ und das BAG dazu aufrufen, das Akkreditierungsprozedere so unkompliziert und effizient als möglich durchzuführen und alles daran zu setzen, hochkompetente Experten zu nominieren. Von diesen hängt ab, ob die Akkreditierung der Weiterbildung wirklichen Nutzen bringt oder ob schliesslich doch nur ein administratives Prozedere abgespult wird. Letzteres darf nicht sein! 